\title{
Gold-catalyzed reactions of oxo-alkynes
}

\author{
Nitin T. Patil and Yoshinori Yamamoto* \\ Department of Chemistry, Graduate School of Science, Tohoku University, \\ Sendai 980-8578, Japan \\ E-mail:yoshi@mail.tains.tohoku.ac.jp
}

\section{Dedicated to Professor Lutz Tietze on the occasion of his $65^{\text {th }}$ Birthday}

\begin{abstract}
Gold (I) and gold (III) complexes show unique catalytic activities toward alkynes; both inter and intramolecular addition of nucleophiles to alkynes is promoted in the presence of gold catalysts. This review focuses on the gold catalyzed reactions of alkynes tethered with carbonyl groups along with their interesting mechanistic aspects.
\end{abstract}

Keywords: Gold catalysis, alkynals, alkynones, domino reactions

\section{Introduction}

The formation of C-C and C-X bonds by the use of transition metal catalysts is one of the most interesting and intriguing subjects in organic chemistry. The formation of these bonds by using various transition metals such as $\mathrm{Pd}, \mathrm{Ni}, \mathrm{Ru}, \mathrm{Rh}$ has been extensively investigated and documented in the literature. ${ }^{1}$ The catalysis of organic reactions by gold compounds has recently been shown to be a powerful tool in organic synthesis. ${ }^{2}$ This chemistry is also valuable in constructing complex molecules. Although gold is considered as an expensive metal, the unique catalytic properties exhibited by the various gold complexes have encouraged organic chemists to explore the viability of these complexes as catalysts. Likewise other transition metals, gold salts are capable of forming several bonds in one pot, without isolating any intermediates, commonly referred as domino ${ }^{3}$ or tandem reactions. It is obvious that this type of reactions would allow the minimization of waste elements and most importantly the reaction can be performed with high atom economy. ${ }^{4}$ Over the decades the usefulness of gold catalyst has been realized and has drawn the attention of numerous research groups, which has been reflected in a number of research publications in the literature. Cationic gold (I) and gold (III) show unique activities toward alkynes, promoting the nucleophilic addition of a variety of functional groups both inter- and intramolecularly. As a part of continuing interest on gold catalysis, we were 
interested in summarizing the gold catalyzed processes of alkynals, alkynones and alkynoates since the products obtained through these processes are valuable building blocks. This review focuses on the gold catalyzed reactions of alkynes tethered with carbonyl groups (Fig 1) along with their interesting mechanistic aspects.

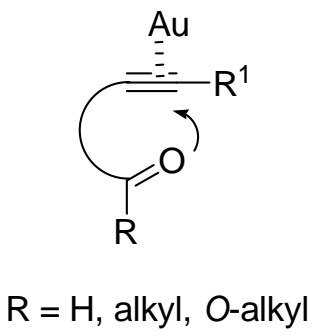

Figure 1

Recently, we reported $\mathrm{AuCl}_{3}$-catalyzed formal $[4+2]$ benzannulation between $o$ alkynylbenzaldehydes 1 and alkynes 2 (eq 1). ${ }^{5}$ Various naphthyl ketones $\mathbf{3 a} / \mathbf{3 b}$ were obtained in good to high yields. It was found that regioselectivity was strongly dependent on the substituent on alkynes. For instance when $\mathrm{R}^{1}=\mathrm{C}_{3} \mathrm{H}_{7}$ and $\mathrm{R}^{2}=\mathrm{H}$, the regioisomer 3a predominates, on the other hand, when $\mathrm{R}^{1}=\mathrm{COCH}_{3}$ and $\mathrm{R}^{2}=\mathrm{H}$, the regioisomer $3 \mathbf{b}$ predominates.

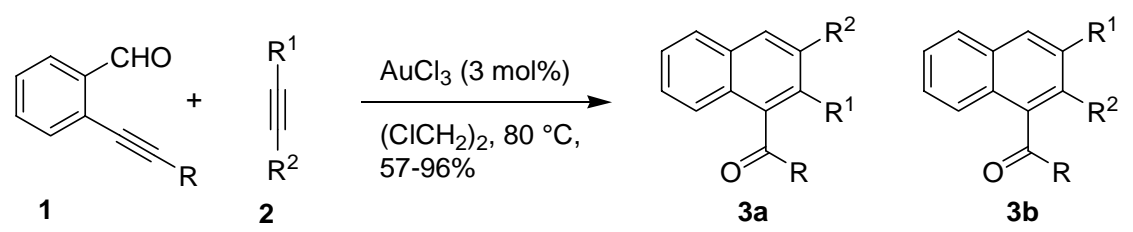

A plausible mechanism for the $\mathrm{AuCl}_{3}$-catalyzed formal [4+2] benzannulation is shown (Scheme 1). The coordination of the triple bond of 1 to $\mathrm{AuCl}_{3}$ enhances the electrophilicity of alkyne and the subsequent nucleophilic attack of the carbonyl oxygen to the electron-deficient alkyne would form the intermediate auric ate complex 5 . ${ }^{6}$ The Diels-Alder type $[4+2]$ cycloaddition of $\mathbf{5}$ with an alkyne $\mathbf{2}$ would occur as shown in $\mathbf{6}$ to form the intermediate 7. The subsequent bond rearrangement, as shown in 7 with arrows, would afford the naphthalene derivatives 3 and regenerate $\mathrm{AuCl}_{3}$. 


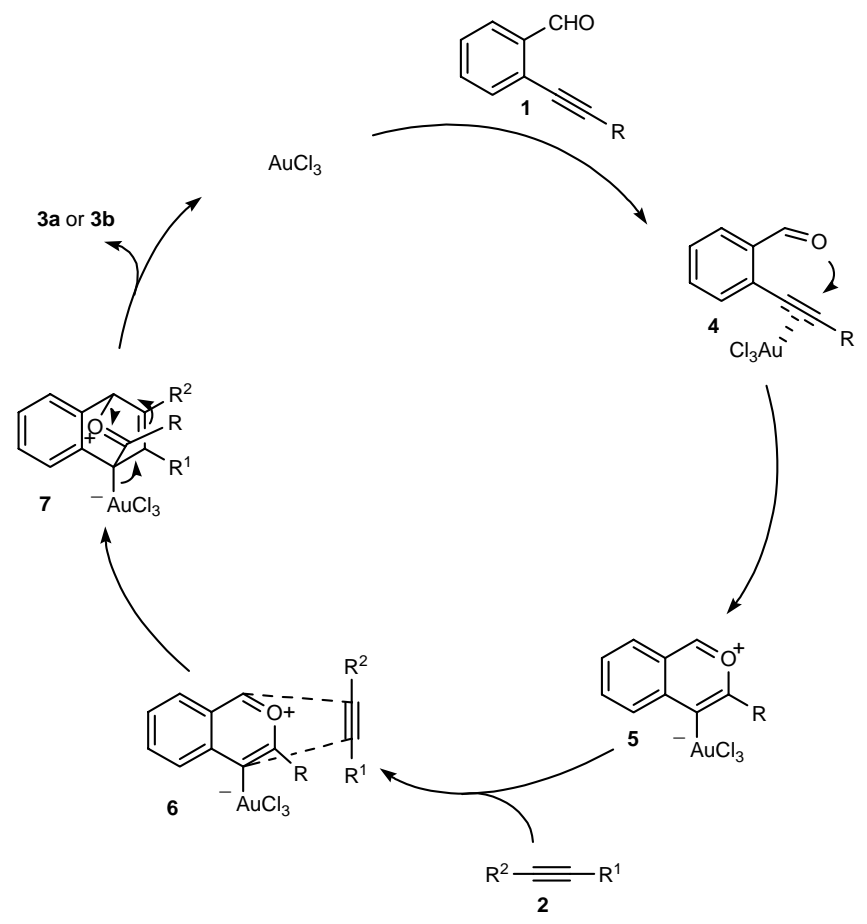

\section{Scheme 1}

The intramolecular version of this reaction was also reported by us (eqs 2 and 3 ). ${ }^{7}$ Treatment of the tethered alkynyl enynones $\mathbf{8}$, in which a carbon chain is attached to the carbonyl group, with a catalytic amount of $\mathrm{AuBr}_{3}$ in $\left(\mathrm{ClCH}_{2}\right)_{2}$ gave the naphthyl ketones 9 in good to high yields (eq 2, top-down approach). Analogously, the $\mathrm{AuBr}_{3}$-catalyzed benzannulations of 10, in which a carbon tether is extended from the alkynyl terminus, also proceeded smoothly, and the cyclized naphthyl ketones 11 were obtained in high yields (eq 3, bottom-up approach).

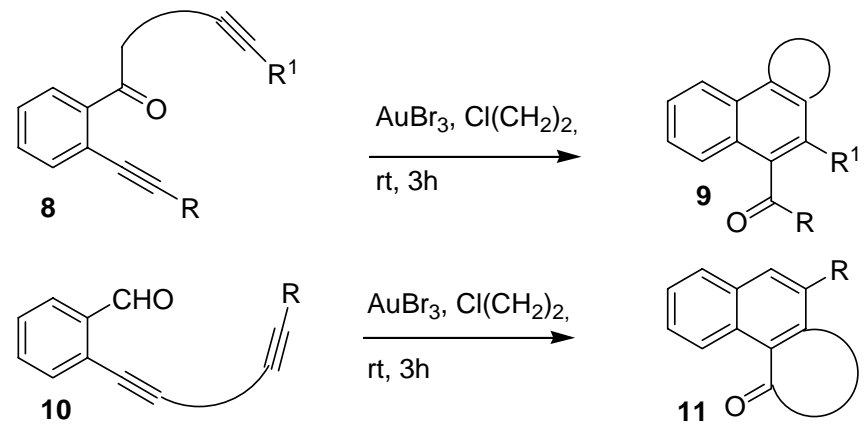

A successful application of this methodology has been made for total synthesis of (+)ochromycinone and (+)-rubiginone $\mathrm{B}_{2}{ }^{8}$ The chiral alkynal 12 was subjected to intramolecular [4+2] benzannulation reaction in the presence of $2 \mathrm{~mol} \% \mathrm{AuCl}_{3}$ to afford (+)-Rubiginone 13. $(+)$-Ochromycinone 14 was easily obtained via demethylation of -OMe group by $\mathrm{BCl}_{3}$. 


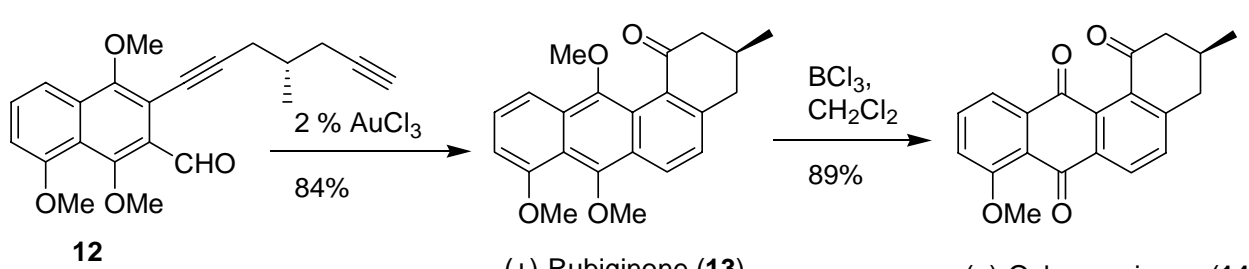

(+)-Rubiginone (13)

(+)-Ochromycinone (14)

\section{Scheme 2}

The application ${ }^{9}$ of this methodology has also been reported recently by Dyker et al. for the total synthesis of rac-heliophenanthrone 15 (eq 4). It was found that gold catalyst gave lower yield $(34 \%)$ for the benzannulation of 16, however, the use of $\mathrm{PtCl}_{2}$ proved beneficial giving the product in $71 \%$ yield. The benzannulation product 17 thus obtained was converted into heliophenanthrone 15.
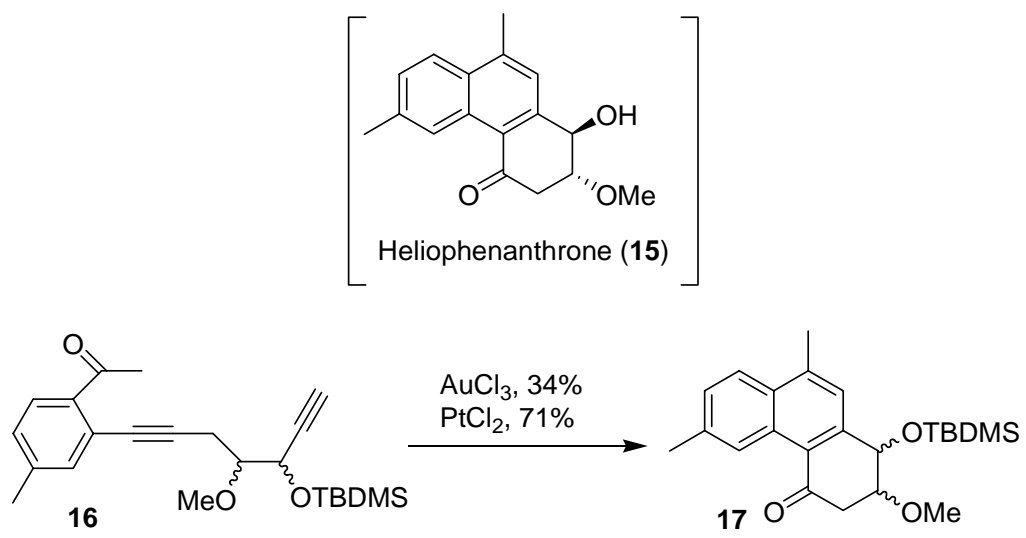

mixture of diastereomers

An innovative extension of the above approach by $\mathrm{Oh}$ and coworkers involved the synthesis of $[6,7, n]$ tricyclic compounds 19 via [3+2] cycloaddition of 18 (eq 5). ${ }^{10}$ It is interesting to note that only trace amounts of [4+2] benzannulation products were obtained in each case. Since the main structural feature distinguishing 18 from 10 is the gem-ester group, the author argued that Thorpe-Ingold effect might be playing some role in favoring the formation of the five membered ring products via intermediate 20. 


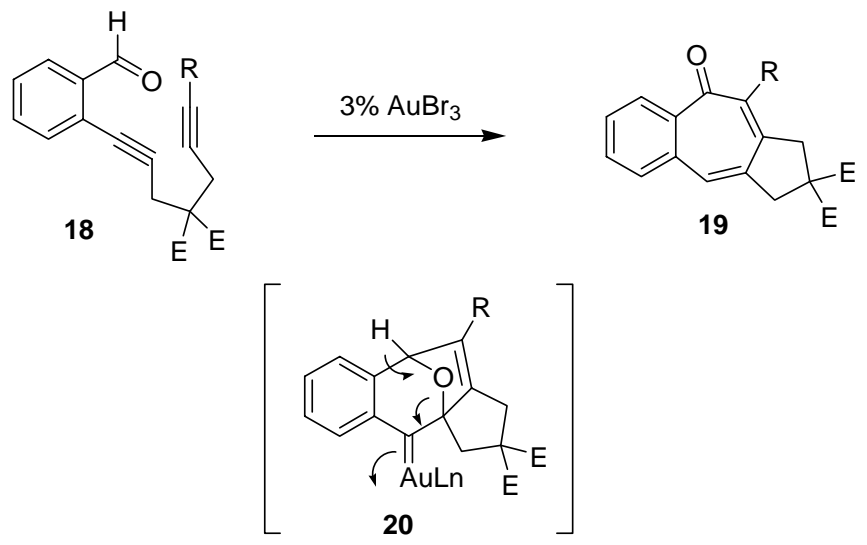

We have reported [4+2] benzannulation between the pyrylium intermediates, formed by the nucleophilic attack of carbonyl oxygen to gold- coordinated alkyne in $\mathbf{1}$, with carbonyl compounds 21. ${ }^{11}$ Functionalized naphthalenes 22 or 23 were obtained in good to high yields by heating the substrates at $100{ }^{\circ} \mathrm{C}$ in 1,4-dioxane in the presence of $\mathrm{AuBr}_{3}$ (eq. 6).

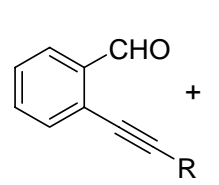

1<smiles>[R]CC([R])=O</smiles>

21<smiles>[R]C(=O)c1c([R])cc2ccccc2c1[R]</smiles>

22<smiles>[R]c1cc2ccccc2cc1[R]</smiles>

23

A plausible mechanism for the present benzannulation is shown in Scheme 3. The gold ate complex 5 was generated from 1 as described previously. The reverse-electron-demand-type Diels-Alder reaction of 5 with the enol 24, derived from 21, followed by dehydration would generate the intermediate 26 through 25. The subsequent bond rearrangement, as shown in 26 with arrows, would afford the naphthyl ketone derivative 22 or 23 with regeneration of $\mathrm{AuBr}_{3}$. 


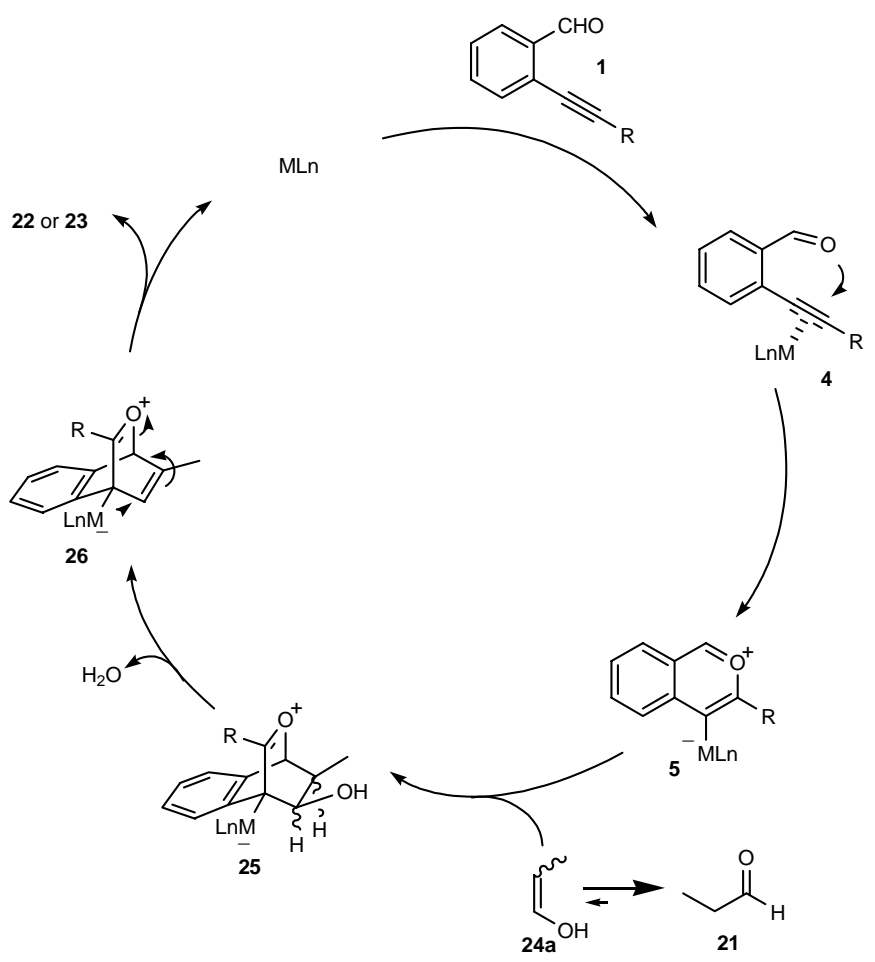

\section{Scheme 3}

Toste et al. developed ${ }^{12} \mathrm{Au}(\mathrm{I})$ catalyzed synthesis of cyclopentenones 28 by the rearrangement of 1-ethynyl-2-propenyl pivaloates 27 (eq. 7). The reactions are tolerant of substitutions at the acetylenic and olefinic positions (except for Z-olefins) providing access to a wide range of cyclopentenones under exceptionally mild conditions. One of the important features of this reaction is that enantio-enriched cyclopentenones could be prepared by cyclization of enantiomerically enriched propargyl alcohols. The high degree of chirality transfer in these rearrangements was observed.

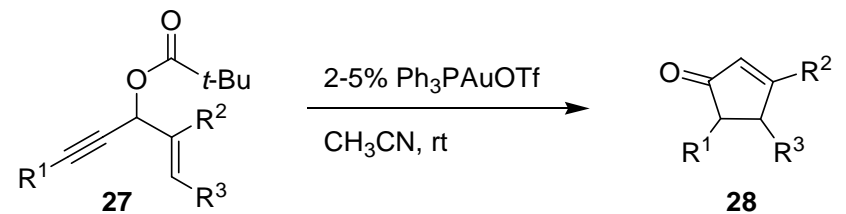

Mechanistically the reaction is quite interesting (Scheme 4). Intramolecular 1,2-addition of the ester oxygen onto the alkyne, induced by coordination of the alkyne to a cationic gold(I) complex, affords the vinyl gold species 28. This cyclization of $\mathbf{2 8}$ produces the cationic intermediate 30 via the transition state 29 , which upon elimination of cationic gold(I) affords the diene 31. Finally, the cyclopentadiene $\mathbf{3 1}$ is hydrolyzed to the cyclopentenone $\mathbf{2 8}$. 


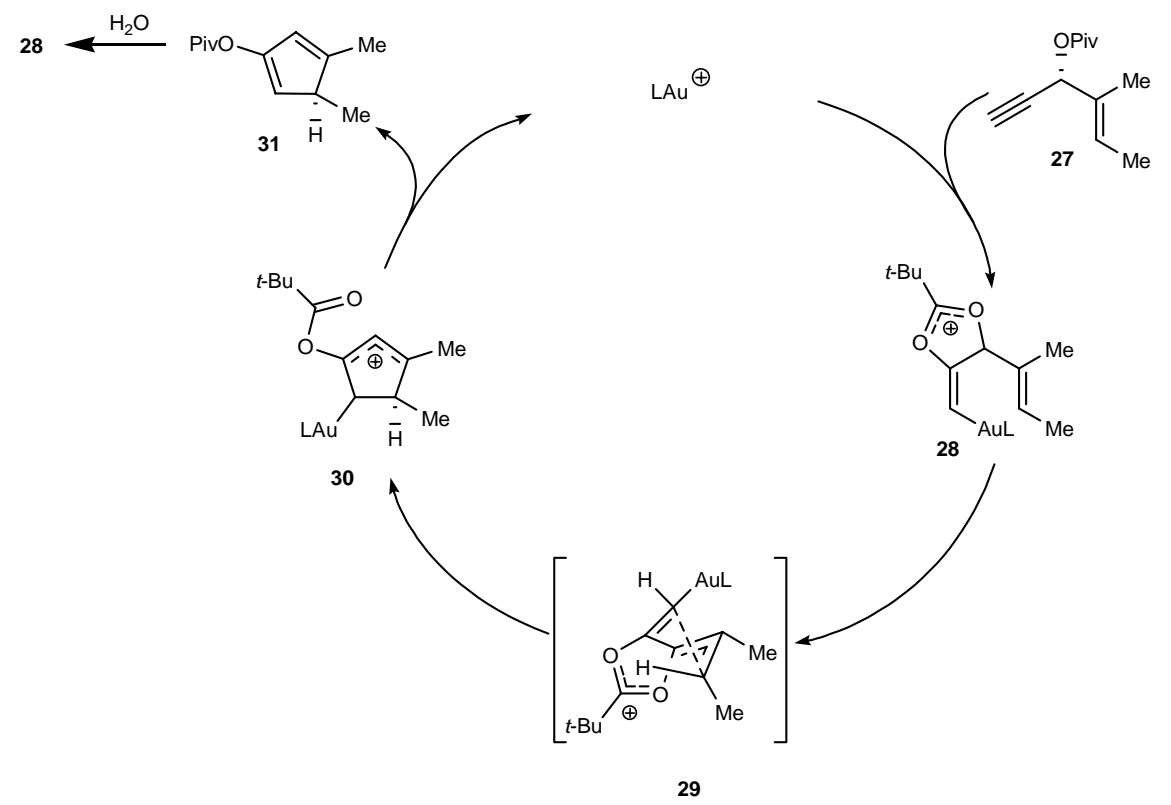

\section{Scheme 4}

Zhang reported the synthesis of highly functionalized 2,3-indoline-fused cyclobutanes 33 from 32 catalyzed by cationic gold (eq 8). ${ }^{13}$ It was proposed that the catalyst played dual role for activating both propargylic esters and the in situ generated allenylic esters.

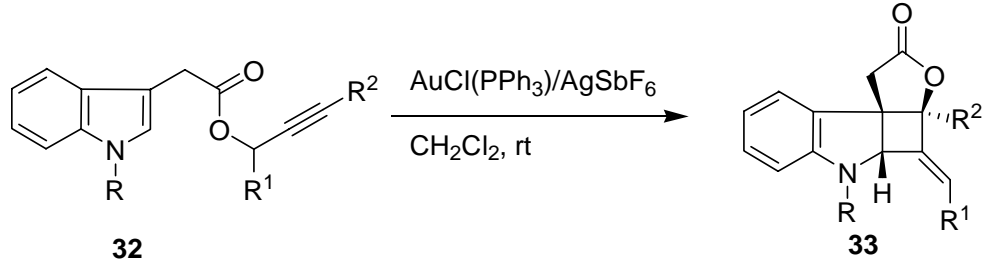

The proposed mechanism for the formation of the cyclobutane 33 is shown in Scheme 5. Activation of the C-C triple bond in propargylic ester 32 by $\left[\mathrm{Au}\left(\mathrm{PPh}_{3}\right)\right]^{+}$promotes a 3,3rearrangement of the indole-3-acetoxy group, which leads to the formation of allenylic ester 37. The allene moiety of 37 was further activated by the cationic $\mathrm{Au}(\mathrm{I})$ complex, resulting in the formation of oxonium ion 38. The cyclobutane 33 is produced via the $\mathrm{C}-\mathrm{C}$ bond formation between the oxonium carbon of $\mathbf{3 8}$ and the C-3 carbon of the indole ring, followed by intramolecular trapping of the iminium with the alkenylgold(I). 


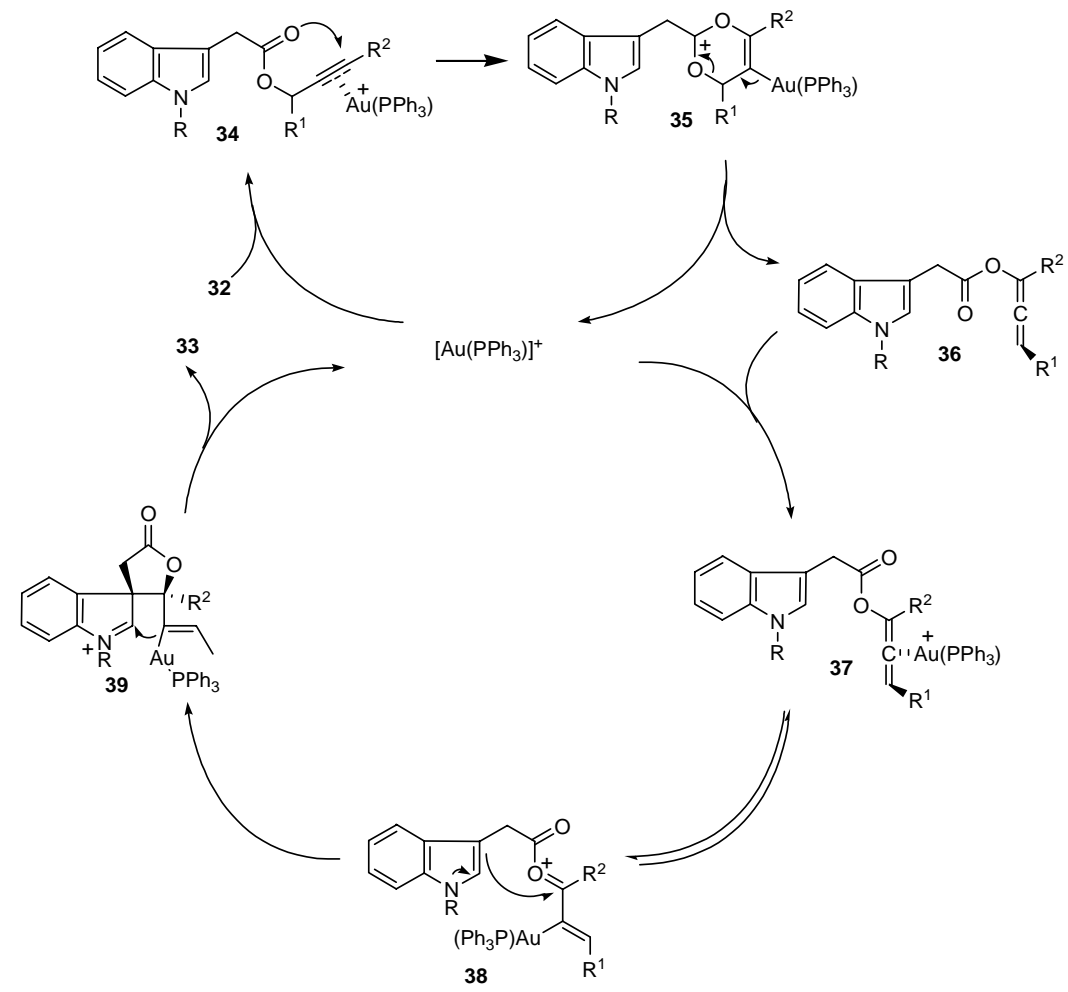

\section{Scheme 5}

A recent report by the same author described gold catalyzed highly efficient synthesis of cyclopentenones $\mathbf{4 1}$ from propargylic esters $\mathbf{4 0}$ via tandem 3,3-rearrangement and the Nazarov reaction (eq 9). ${ }^{14}$

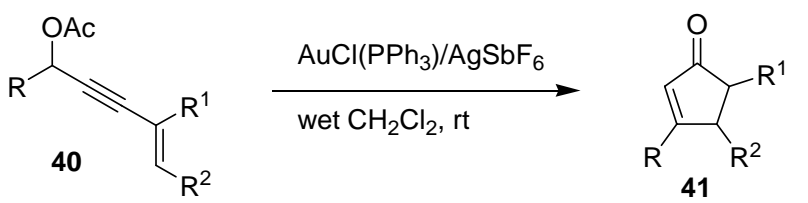

The mechanism of the reaction is presented in Scheme 6. The allenylic acetate 42 generated in situ via cationic $\mathrm{Au}(\mathrm{I})$-catalyzed [3,3]-rearrangement of the corresponding propargylic acetate is further activated by the $\mathrm{Au}(\mathrm{I})$ catalyst leading to pentadienylic cation 43. $4 \pi$-Electron closure of $\mathbf{4 3}$ forms the $\mathrm{Au}$ - containing cyclopentenylic cation $\mathbf{4 4}$, which is in resonance with $\mathrm{Au}$ carbenoid species 45. [1,2]-Hydride shift in $\mathbf{4 5}$ gives $\mathbf{4 6}$ after subsequent elimination and regeneration of the cationic $\mathrm{Au}(\mathrm{I})$ catalyst. 


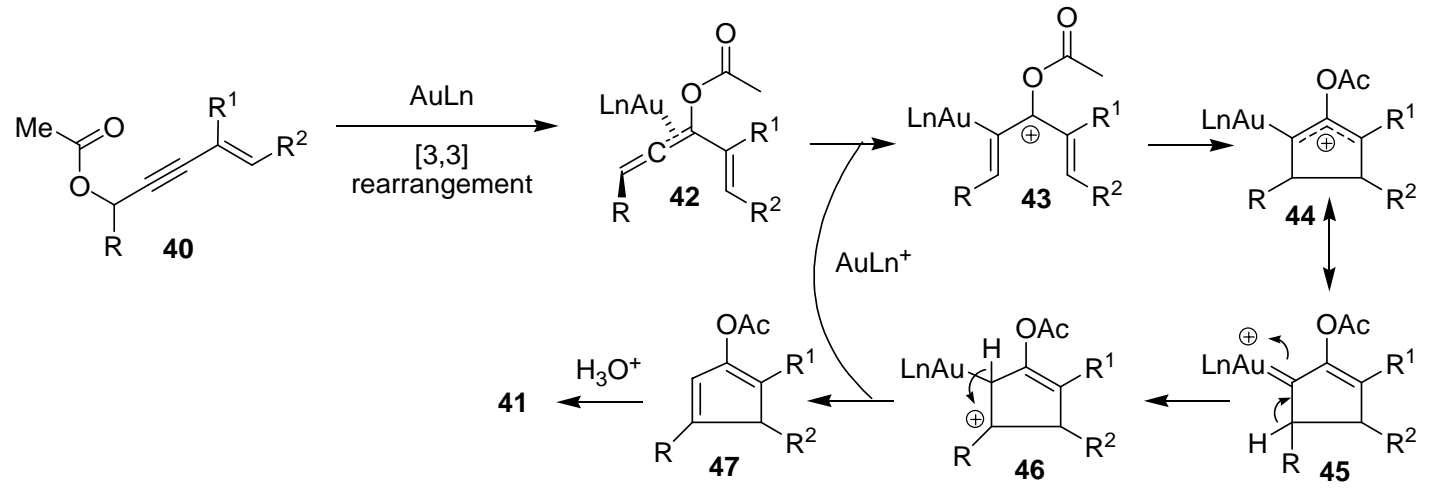

\section{Scheme 6}

Furstner et al. described the $\mathrm{AuCl}_{3}$ catalyzed rearrangement of propargylic acetates for the synthesis of terpene derivatives (eq 10). ${ }^{15}$ Complexation of gold catalyst to alkyne renders alkynes susceptible to attack the carbonyl oxygen to form gold carbene $\mathbf{5 2}$ through intermediate 50 and 51. The insertion of carbene 52 was then took place into the tethered alkene to form the product 49.

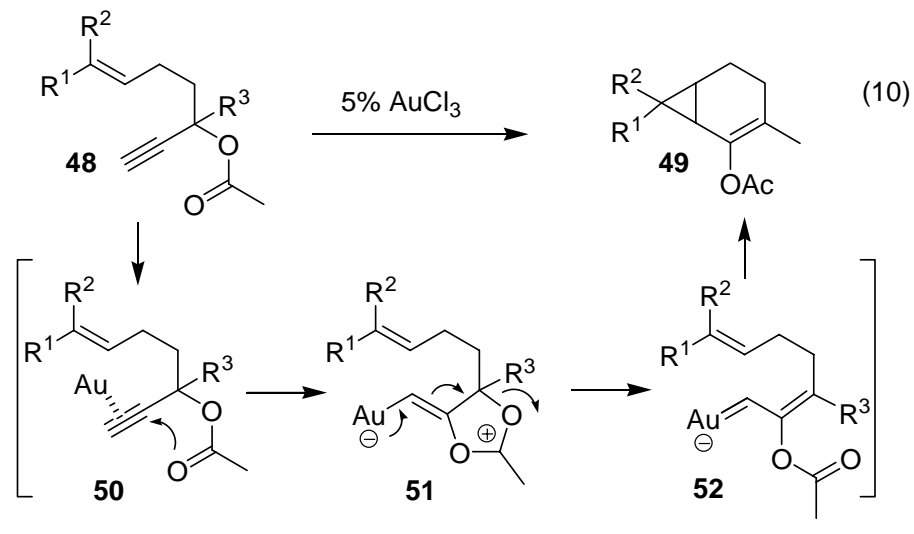

Recently, Toste has developed a gold(I)-catalyzed cyclopropanation of olefins 54 using propargyl esters 53 as gold-(I)-carbene precursors (eq 11). ${ }^{16}$ The attack of carbonyl oxygen to the gold coordinated alkyne would produce intermediate 57 via 56, which on subsequent rearrangement as shown by the arrow would provide gold carbene complex 58. The carbene complex 58 thus formed could then be inserted into the olefin to provide cyclopropanation products. The highest enantioselectivity of $85 \%$ was achieved using DTBM-SEGPHOS-gold (I) catalyst. 


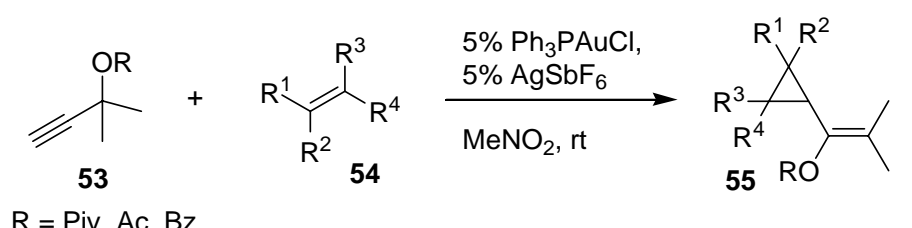

$\mathrm{R}=\mathrm{Piv}, \mathrm{Ac}, \mathrm{Bz}$

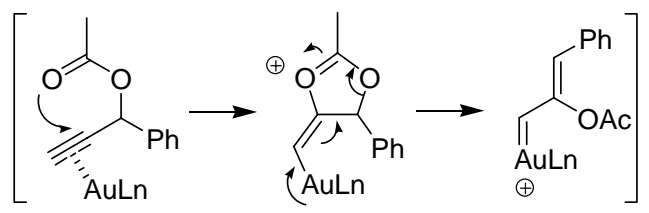

56

57

The chemistry has also been applied by Porco for the synthesis of various azaphilones, which are known to be a component of many natural products. Gold catalyzed cycloisomerization of $\mathrm{O}$-alkynylbenzaldehydes $\mathbf{5 9}$ into 2-benzopyrylium salts and subsequent oxidation by using IBX in conjunction with phase transfer catalyst provided products $\mathbf{6 0}$ in high yields (eq 12). ${ }^{17}$

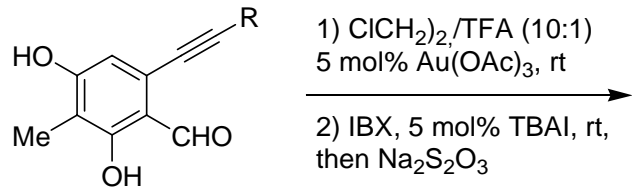

59

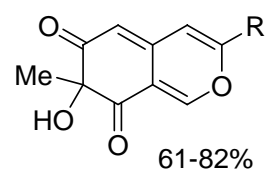

60

The reaction of propargyl ketones such as $\mathbf{6 1}$ in the presence of $0.1 \mathrm{~mol} . \% \mathrm{AuCl}_{3}$ gave the furan 62 in essentially quantitative yield (eq 13) ${ }^{18}$ On the other hand, with palladium as a catalyst, $100{ }^{\circ} \mathrm{C}$ temperature is needed in order to proceed the reaction. A novel cascade cyclization of the propargyl ketone 63 in the presence of $\mathrm{AuCl}_{3}$ was also reported (eq. 14). The author proposed the intermediacy of $\mathbf{6 4}$ for this cascade cyclization.
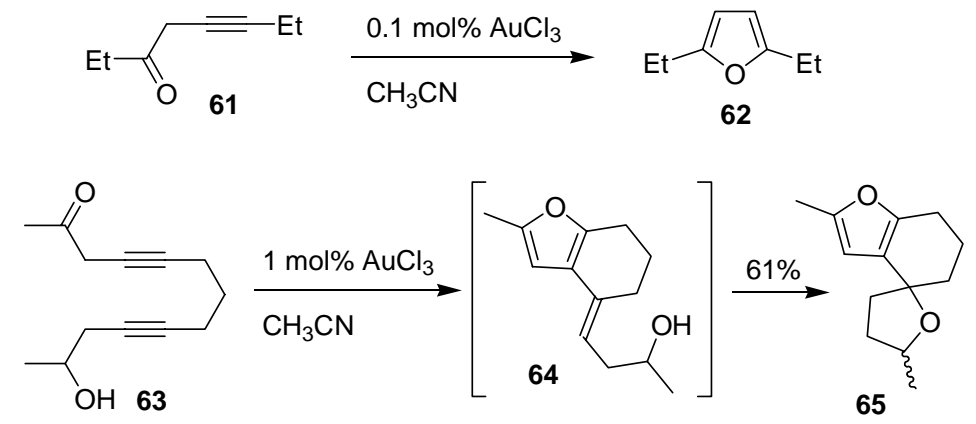

Recently, Larock reported an entirely new approach for the novel cyclization of 2-(1alkynyl)-2-alken-1-ones 66 with nucleophiles in the presence of catalytic amounts of $\mathrm{AuCl}_{3}$ which led to the formation of highly substituted furans 67 (eq 15). ${ }^{19}$ An example of nucleophiles 
includes alcohol, activated methylene and electron rich arenes such as $N, N$-dimethylaniline and $N$-methyl indole.

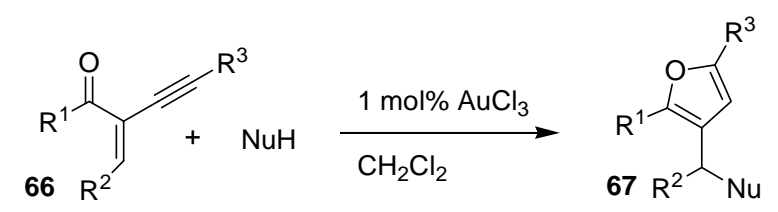

The mechanism of the reaction is depicted in Scheme 7. The coordination of the triple bond of 66 to $\mathrm{AuCl}_{3}$ enhances the electrophilicity of the triple bond, and subsequent nucleophilic attack of the carbonyl oxygen on the electron-deficient triple bond generates carbocation 69. Intermolecular nucleophilic attack on the carbocation and subsequent protonation of the carbongold bond afford furan 67 and regenerate the catalyst $\mathrm{AuCl}_{3}$. The authors ruled out the possibility of an alternative mechanism wherein $\mathrm{AuCl}_{3}$ first acts as a Lewis acid, forming a complex with the carbonyl oxygen thereby facilitating Michael addition since $1 \% \mathrm{AuCl}_{3}$ failed to catalyze the 1,4-addition of methanol to 2-cyclohexenone and methyl vinyl ketone under the standard conditions.

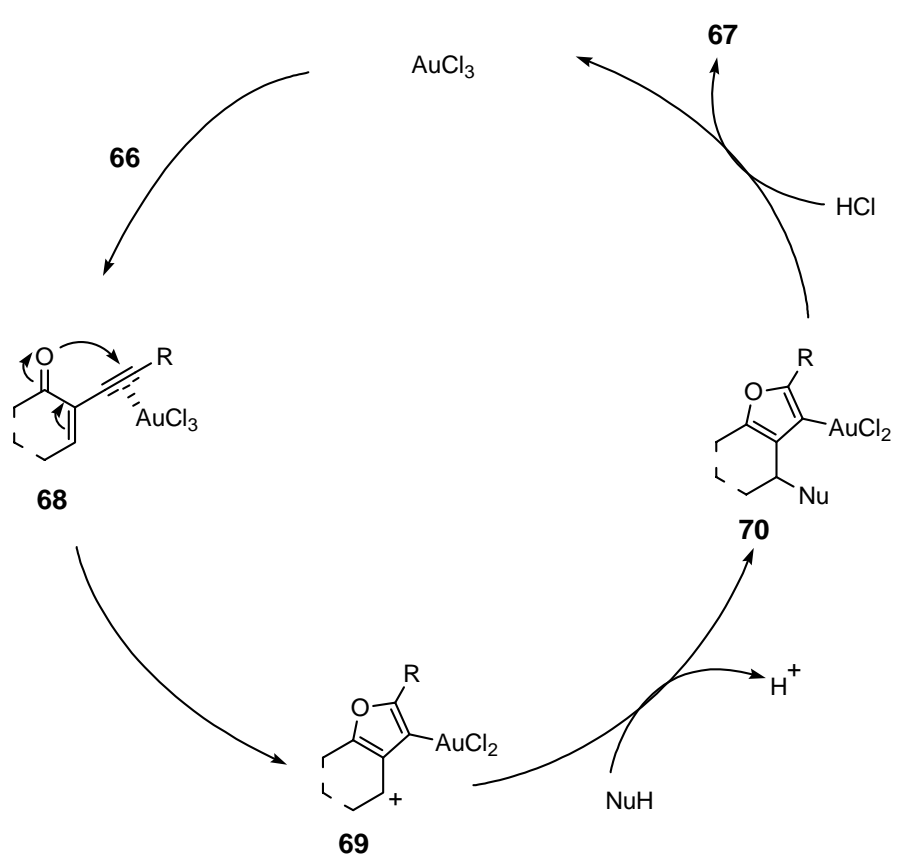

\section{Scheme 7}

Recently, Hashmi and coworkers reported gold catalyzed synthesis of 2,5-disubstituted oxazoles 72 from the corresponding propargylcarboxamides 71 (eq 16). ${ }^{20}$ The addition of amide oxygen to gold co-ordinated alkyne is highly stereospecific as shown is $\mathbf{7 3}$ to form the vinyl gold species $\mathbf{7 4}$ which on protonation and regeneration of catalyst gave products $\mathbf{7 2}$. 


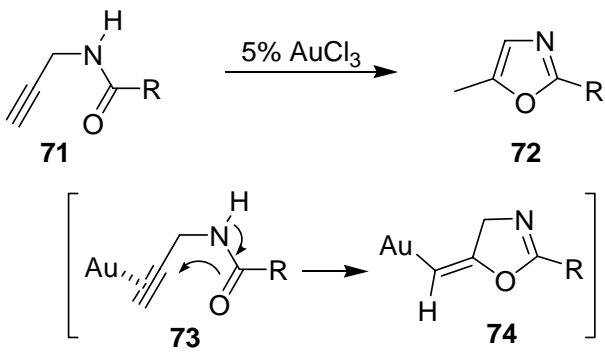

The gold catalyzed rearrangement of propargylic tert-butyl carbonates 75 and 77 into 4alkylidene-1,3-dioxolan-2-ones 76 and 78 was described by Gagosz and Buzas (eqs 17 and 18). ${ }^{21}$ A variety of cyclic carbonates were synthesized under these milder conditions.
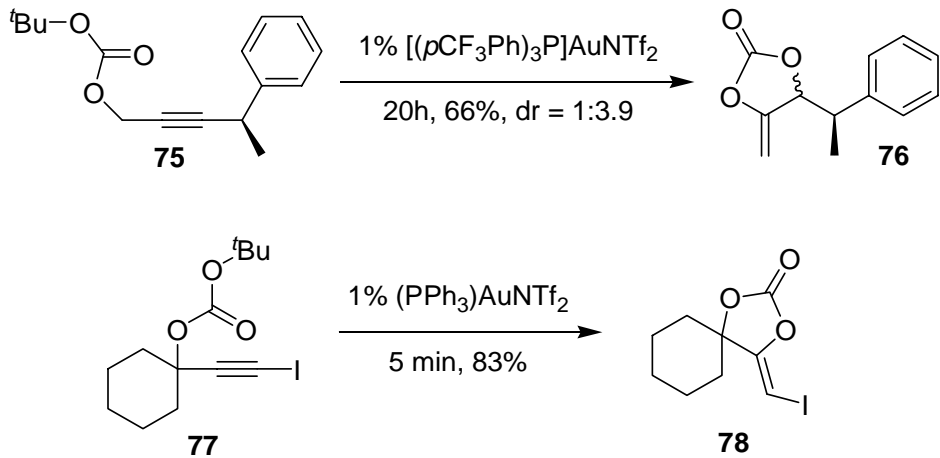

In summary, we have discussed the gold catalyzed reactions of carbonyl compounds tethered with alkynes. Other transition metals are also known to activate alkynes allowing the nucleophilic attack of carbonyls to metal co-ordinated alkynes. However, gold is now becoming more popular because of its efficiency in performing reactions at lower catalyst loading and at room temperature.

\section{References}

1. There are innumerable reports; for instance, see: (a) Nakamura, I.; Yamamoto, Y. Chem. Rev. 2004, 104, 2127. (b) Zeni, G.; Larock, R. C. Chem. Rev. 2004, 104, 2285.

2. Reviews: (a) Thompson, D. Gold Bull., 1998, 31, 111. (b) Thompson, D. Gold Bull., 1999, 32, 12. (c) Bond, G. C. Catal. Today, 2002, 72, 5. (d) Dyker, G. Angew. Chem., Int. Ed., 2000, 39, 4237. (e) Hashmi, A. S. K. Gold Bull., 2003, 36, 3. (f) Hashmi, A. S. K. Gold Bull., 2004, 37, 51. (g) Arcadi, A.; Giuseppe, S. D. Curr. Org. Chem., 2004, 8, 795. (h) Hoffmann-Roder, A.; Krause, N. Org. Biomol. Chem., 2005, 3, 387. (i) Hashmi, A. S. K. Angew. Chem., Int. Ed., 2005, 44, 6990. (j) Ma, S.; Yu, S.; Gu, Z. Angew. Chem., Int. Ed., 2005, 44, 2. 
3. (a) Poli, G., Giambastiani, G.; Heumann, A. Tetrahedron, 2000, 56, 5959. (b) Heumann, A.; Reglier, M. Tetrahedron 1996, 52, 9289. (c) Meijere, A. D., Brase, S. J. Organomet. Chem. 1999, 576, 88. (d) Tietze, L. F. Chem. Rev. 1996, 96, 115. (e) Balme, G.; Bossharth, E.; Monteiro, N. Eur. J. Org. Chem. 2003, 4101. (f) Ramon, D. J.; Yus, M. Angew. Chem. Int. Ed. 2005, 44, 1602.

4. (a) Trost, B. M. Science 1991, 254, 1471. (b) Trost, B. M. Angew. Chem., Int. Ed. 1995, 34, 259. (c) Sheldon, R. A. Pure Appl. Chem. 2000, 72, 1233.

5. (a) Asao, N.; Nogami, T.; Lee, S.; Yamamoto, Y. J. Am. Chem. Soc. 2003, 125, 10921. (b) Asao, N.; Takahashi, K.; Lee, S.; Kasahara, T.; Yamamoto, Y. J. Am. Chem. Soc. 2002, 124, 12650.

6. For a DFT study, see: Straub, B. F. J. Chem. Soc., Chem. Commun. 2004, 1726.

7. Asao, N.; Sato, K.; Menggenbateer, Yamamoto Y. J. Org. Chem. 2005, 70, 3682.

8. Sato, K.; Asao, N.; Yamamoto Y. J. Org. Chem. 2005, 70, 8977.

9. Dyker, G.; Hildebrandt, D. J. Org. Chem. 2005, 70, 6093.

10. Kim, N.; Kim, Y.; Park, W.; Sung, D.; Gupta, A. K.; Oh, C. H. Org. Lett. 2005, 7, 5289.

11. Asao, N.; Aikawa, H.; Yamamoto Y. J. Am. Chem. Soc. 2004, 126, 7458.

12. Shi, X.; Gorin, D. J.; Toste, F. D. J. Am. Chem. Soc. 2005, 127, 5802.

13. Zhang, L. J. Am. Chem. Soc. 2005, 127, 16804.

14. Zhang, L.; Wang, S. J. Am. Chem. Soc. 2006, 128, 1442.

15. Furstner, A.; Hannen, P. J. Chem. Soc., Chem. Commun. 2004, 2546. For the related processes, see: (b) Mamane, V.; Gress, T.; Krause, H.; Furstner, A. J. Am. Chem. Soc. 2004, 126, 8654. (c) Gagosz, F. Org. Lett. 2005, 7, 4129.

16. Johansson, M. J., Gorin, D. J.; Staben, S. T.; Toste, F. D. J. Am. Chem. Soc. 2005, 127, 18002.

17. Zhu, J.; Germain, A. R.; Porco, J. A. Angew. Chem., Int. Ed., 2004, 43, 1239.

18. Hashmi, A. S. K.; Schwarz, L.; Choi, J.-H.; Frost, T. M. Angew. Chem., Int. Ed., 2000, 39, 2285.

19. Yao, T.; Zhang, X.; Larock, R. C. J. Am. Chem. Soc. 2004, 126, 11164.

20. Hashmi, A. S. K.; Weyrauch, J. P.; Frey, W.; Bats, J. W. Org. Lett. 2004, 6, 4391.

21. Buzas, A.; Gagosz, F. Org. Lett. 2006, 8, 515.

\section{Authors' biographical data}

Nitin Patil was born in Achegaon (a small village in the Jalgaon district of Maharashtra) in India in 1975. After completing his master studies in 1997 at North Maharashtra University, he joined Dr. Dilip Dhavale's research group as a CSIR-JRF at University of Pune for his Ph.D. work. He completed his doctoral study in 2002 on the synthesis of polyhydroxylated piperidine and indolizidine alkaloids. After working for nine months as a postdoctoral fellow at Goettingen University, with Professor Christoph Schneider on enantioselective opening of epoxides, he 
shifted to Tohoku University, Japan, as a JSPS Postdoctoral Fellow to work with Professor Yoshinori Yamamoto. Presently, he has been working as Assistant Professor of Organic Chemistry in the same laboratory. His research interest includes transition metal and Lewis acid mediated development of new synthetic methods, asymmetric catalysis, and synthesis of biologically important natural and unnatural compounds. He has more than 30 research publications in international peer-reviewed journals including book chapters and reviews.

Yoshinori Yamamoto was born in Kobe, Japan, and received his M.S. and Ph.D. degrees from Osaka University. In 1970 he was appointed as an Instructor at Osaka University, after which he went to Professor H. C. Brown's research group at Purdue University, as a Postdoctoral Associate (1970-1972). In 1977 he was appointed as an Associate Professor at Kyoto University. In 1986 he moved to Tohoku University to take up his present position, Professor of Chemistry. He also holds a Professorship at IMRAM, Tohoku. He was awarded the Chemical Society of Japan Award for Young Chemists (1976), the Chemical Society of Japan Award (1996), and the Humboldt Research Award (2002). He is the Regional Editor of Tetrahedron Letters and Volume Editor of Science of Synthesis, and he was the President of the International Society of Heterocyclic Chemistry (2000-2001). He is the project leader of the 21 Century COE Program of MEXT "Giant Molecules and Complex Systems, Chemistry Group of Tohoku University" (2002-2006). He has a wide range of research interests in synthetic organic and organometallic chemistry. His recent work focused on the use of transition-metal complexes and Lewis acids as catalytic reagents in organic synthesis and synthesis of complex natural products. 